\title{
Relativistic Effects on the NMR Parameters of Si, Ge, Sn and Pb Alkynyl Compounds: Scalar versus Spin-Orbit Effects
}

\author{
Taye B. Demissie ${ }^{1, \text { a) }}$ \\ Hylleraas Centre for Quantum Molecular Sciences, Department of Chemistry, UiT The Arctic University of Norway, \\ 9037 Tromsø, Norway
}

The NMR chemical shifts and indirect spin-spin coupling constants of 12 molecules containing ${ }^{29} \mathrm{Si},{ }^{73} \mathrm{Ge},{ }^{119} \mathrm{Sn}$ and ${ }^{207} \mathrm{~Pb}\left(\mathrm{X}(\mathrm{CCMe}){ }_{4}, \mathrm{Me}_{2} \mathrm{X}(\mathrm{CCMe})_{2}\right.$ and $\left.\mathrm{Me}_{3} \mathrm{XCCH}\right)$ are presented. The results are obtained from non-relativistic as well as two- and four-component relativistic density functional theory calculations. The scalar and spin-orbit relativistic contributions as well as the total relativistic corrections are determined. The main relativistic effect in these molecules is not due to spin-orbit coupling, but rather to the scalar relativistic contraction of the s-shells. The correlation between the calculated and experimental indirect spin-spin coupling constants showed that the four-component relativistic density functional theory (DFT) approach using the hybrid exchange-correlation functional PBE0 gives results in good agreement with experimental values. The indirect spin-spin coupling constants calculated using the spin-orbit zeroth order regular approximation (SO-ZORA) together with the hybrid PBE0 functional and JCPL basis sets are in good agreement with the results obtained from the four-component relativistic calculations. For the coupling constants involving the heavy atoms, the relativistic corrections are of the same order of magnitude compared to the nonrelativistically calculated results. Based on the comparisons of the calculated results with available experimental values, the best results for all the chemical shifts and non-existing indirect spin-spin coupling constants for all the molecules are reported, hoping that these accurate results will be used to benchmark future DFT calculations. The present study also demonstrates that the four-component relativistic DFT method has reached a level of maturity that makes it a convenient and accurate tool to calculate indirect spin-spin coupling constants of 'large' molecular systems involving heavy atoms.

\section{INTRODUCTION}

Nuclear Magnetic Resonance (NMR) is a powerful spectroscopic technique that provides detailed information that are important for chemical structure studies. The NMR chemical shifts and spin-spin coupling constants can be determined using either experimental techniques or highly accurate computational approaches. ${ }^{1-5}$ In the latter case, the NMR shielding tensor of nucleus A $\left(\sigma_{\mathrm{A}}\right)$ is expressed as the second derivative of energy with respect to the nuclear magnetic dipole moment $\left(\vec{\mu}_{\mathrm{A}}\right)$ and the applied external magnetic field, $\vec{B}: 3,5,6$

$$
\sigma_{\mathrm{A}}=\left.\frac{\partial^{2} E\left(\vec{\mu}_{\mathrm{A}}, \vec{B}\right)}{\partial \vec{\mu}_{\mathrm{A}} \partial \vec{B}}\right|_{\vec{B}=0, \vec{\mu}_{\mathrm{A}}=0}
$$

which is then used to predict the chemical shifts $\left(\delta_{\mathrm{A}}\right)$ as the differences between the absolute shielding constant of a reference compound and the calculated absolute shielding constants of each nucleus of interest in a molecule. The reduced nuclear spin-spin coupling constant $\mathrm{K}$ involving two nuclei A and B is obtained from: ${ }^{3,5,6}$

$$
\mathrm{K}_{\mathrm{A}, \mathrm{B}}=\left.\frac{\partial^{2} E\left(\vec{\mu}_{\mathrm{A}}, \vec{\mu}_{\mathrm{B}}\right)}{\partial \vec{\mu}_{\mathrm{A}} \partial \vec{\mu}_{\mathrm{B}}}\right|_{\vec{\mu}_{\mathrm{A}}=0, \vec{\mu}_{\mathrm{B}}=0}
$$

where $\vec{\mu}_{\mathrm{A}}$ and $\vec{\mu}_{\mathrm{B}}$ are the nuclear magnetic dipole moments of nuclei $\mathrm{A}$ and $\mathrm{B}$, respectively. The reduced nuclear spin-spin coupling constant $\mathrm{K}$ is converted to the

a)Corresponding Email: taye.b.demissie@uit.no indirect spin-spin coupling constant $\mathrm{J}$ using the gyromagnetic ratios of the nuclei $\mathrm{A}$ and $\mathrm{B} .^{5,6}$

There have been significant advances in the development of method for calculating absolute shielding and indirect spin-spin coupling constants. ${ }^{3,5,6}$ At the fourcomponent level of theory, the first Dirac-Hartree-Fock (DHF) calculations of indirect spin-spin coupling constants were reported by Visscher and coworkers, ${ }^{7}$ whereas the first four-component relativistic DFT implementation of indirect spin-spin couplings was reported by Repisky and coworkers. ${ }^{8}$ These methods provide accurate NMR parameters for molecules involving heavy atoms (see for instance Refs. ${ }^{9-13}$ ), making them promising and appropriate methods for the study and spectral interpretation of such molecules. However, much work in the area of application of these methods remains to be done, especially for medium- and large-size molecules involving heavy atoms.

The spin-orbit zeroth order regular approximation (SO-ZORA) has been shown to be an efficient approach for the calculation of NMR parameters of molecules involving heavy atoms. ${ }^{14,15}$ However, the use of full fourcomponent relativistic DFT approaches becomes very important to get accurate results. ${ }^{11-13,16,17}$ In this aspect, the ReSpect program package ${ }^{18}$ is among the efficient four-component relativistic approaches for the calculation of chemical shielding constants ${ }^{19,20}$ and indirect spin-spin coupling constants. ${ }^{8}$

Comparison of two- and four-component relativistic methods for the calculation of spin-spin coupling and shielding constants showed that spin-orbit contributions are dominant for the absolute shielding constants, ${ }^{11-13,17,21}$ whereas scalar effects are found to be 
dominant for the spin-spin coupling constants due to the relativistic increase of density and spin-density at the position of the nucleus. ${ }^{22-24} \mathrm{~A}$ study of the indirect nuclear spin-spin coupling constants of $\mathrm{MH}_{4}(\mathrm{M}=\mathrm{C}, \mathrm{Si}, \mathrm{Ge}, \mathrm{Sn}$, $\mathrm{Pb}$ ) and $\mathrm{Pb}\left(\mathrm{CH}_{3}\right)_{3} \mathrm{H}$ using relativistic four-component DFT calculations indicated that the main relativistic effect in these molecules is not due to the spin-orbit coupling but rather to the scalar relativistic contraction of the s-shells. ${ }^{25}$ The calculated results for the same $\mathrm{MH}_{4}$ molecules (except $\mathrm{PbH}_{4}$ ) using perturbative first-order spin-orbit corrections also showed that the spin-orbit corrections are small. ${ }^{26}$ Overall, the inclusion of relativistic effects in the calculation of NMR parameters is very important even for qualitatively correct results. This is especially important for spin-spin coupling constant since it depends on the behavior of the wave function in the close vicinity of the nuclei. ${ }^{3-5}$

In the present work, the periodic trends and properties of the chemical shifts and indirect spin-spin coupling constants of 12 tetrahedral molecules of silicon, germanium, tin and lead alkynyl compounds $\left(\mathrm{X}(\mathrm{CCMe})_{4}\right.$, $\mathrm{Me}_{2} \mathrm{X}(\mathrm{CCMe})_{2}$ and $\mathrm{Me}_{3} \mathrm{XCCH}$, where $\mathrm{X}={ }^{29} \mathrm{Si},{ }^{73} \mathrm{Ge}$, ${ }^{119} \mathrm{Sn},{ }^{207} \mathrm{~Pb}$, and $\left.\mathrm{Me}=\mathrm{CH}_{3}\right)$ were examined using nonrelativistic and two- and four-component relativistic approaches. The main objectives of the study are: (1) to study the periodic trends of the two NMR parameters using different computational approaches, (2) to analyze the relativistic effects and, (3) to present new, accurate, and benchmark quality results for the non-existent NMR parameters. Moreover, so far, four-component relativistic spin-spin coupling constant calculations have been successfully performed for small and medium size molecules (see for instance $\operatorname{Refs}^{9,21}$ ). In the present work, two molecules with 110 atoms (shown in Fig. 1), in addition to the above twelve molecules, were considered for the calculation of indirect spin-spin coupling constants through one and two bonds, and to compare the calculated results with the corresponding experimental values.

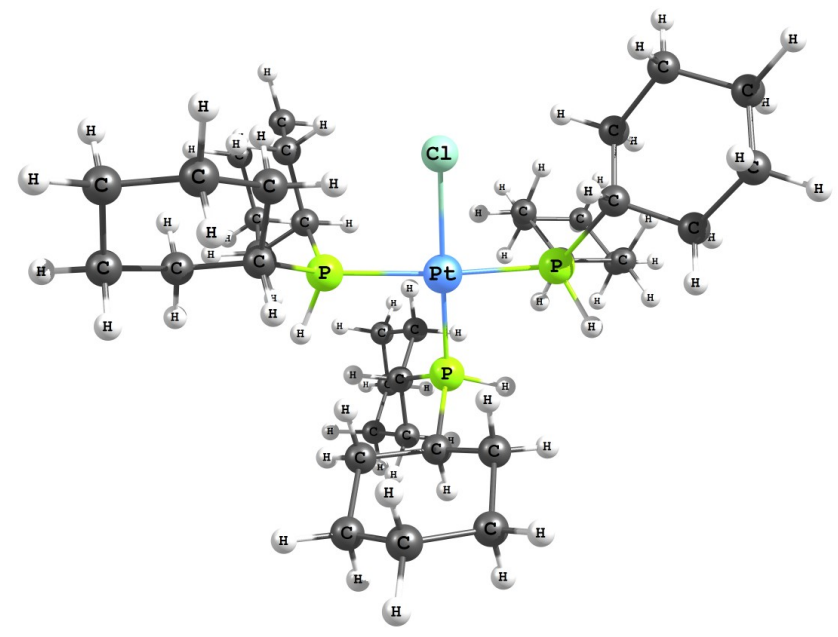

FIG. 1. The geometry of platinum(II)-dicyclohexylphosphine $\left[\mathrm{Pt}\left(\mathrm{PCy}_{2} \mathrm{H}\right)_{3} \mathrm{Cl}\right]^{+}\left(\mathrm{PtC}_{36} \mathrm{P}_{3} \mathrm{H}_{69} \mathrm{Cl}\right)$; palladium in place of platinum for $\left[\mathrm{Pd}\left(\mathrm{PCy}_{2} \mathrm{H}\right)_{3} \mathrm{Cl}\right]^{+}$.

\section{COMPUTATIONAL DETAILS}

The molecular geometries were optimized using the spin-orbit zeroth-order regular approximation (SOZORA) $)^{14,15}$ as implemented in the Amsterdam Density Functional (ADF, version 2016.103) program package ${ }^{27}$ together with the hybrid PBE0 exchange-correlation functional, ${ }^{28}$ Grimme's dispersion correction, ${ }^{29}$ and the all-electron triple- $\zeta$ double polarized (TZ2P) Slater-type basis sets optimized for ZORA computations. ${ }^{30}$ All optimized structures were confirmed to be real minima by performing frequency calculations at the same level of theory.

The NMR chemical shifts and spin-spin coupling constants were calculated using the four-component DiracKohn-Sham (DKS) relativistic Hamiltonian as implemented in a development version of the ReSpect ${ }^{18}$ pro- $^{-}$ gram package. The $\mathrm{PBE}^{31}$ and $\mathrm{PBE}^{28}$ exchangecorrelation functionals together with Dyall's relativistic all-electron core-valence triple- $\zeta$ (dyall-cvtz) basis sets ${ }^{32}$ were used in these four-component relativistic DFT calculations. To study the basis sets dependence, the Dyall's relativistic all-electron core-valence quadruple- $\zeta$ (dyallcvqz) basis sets $^{32}$ were also used. The non-relativistic results were obtained by scaling the speed of light by a factor of 100. To get the scalar relativistic results, in the perturbation-free calculations, all the SO integrals were omitted, while all the four-component operators in the response calculations are kept (see Refs. ${ }^{11,33,34}$ for more details). The finite-size Gaussian-type model was used for the nuclear charge distribution, whereas the pointtype model was employed for the magnetic moment.

The restricted magnetic balance scheme was used for the calculations of the NMR parameters in the ReSpect program package. ${ }^{19,20}$ The spin-orbit contributions $(\Delta \mathrm{SO})$ were calculated as the difference between the full four-component relativistic DFT calculations and the calculations with SO effects removed as described above; whereas the scalar relativistic contributions $(\Delta \mathrm{SC})$ were calculated as differences between the calculations with SO effects removed and the non-relativistic calculations. The relativistic corrections $(\Delta \mathrm{rel})$ were estimated as the difference between the full four-component relativistic (DKS) and the non-relativistic (NR) values, all obtained using the PBE0 exchange-correlation functional and the dyall-cvtz basis sets.

The two-component relativistic absolute shielding and indirect spin-spin coupling constants were calculated based on the SO-ZORA-DFT approach using the NMR and CPL spin-spin coupling modules, ${ }^{35-37}$ respectively, of the ADF program. ${ }^{27}$ The hybrid PBE0 functional together with the TZ2P basis set was used for the SO-ZORA calculations. Additional calculations for the molecules containing lead and platinum were performed using the JCPL basis set. ${ }^{38}$ This basis set combined with the SO-ZORA Hamiltonian and hybrid functionals has been shown to provide results in good agreement with experimental values. ${ }^{38,47-49}$ These JCPL basis sets are available for only 20 atoms, and hence, such calculations were limited to the lead and platinum complexes. However, additional calculations were performed by us- 
ing the JCPL basis sets for the other atoms $(\mathrm{H}, \mathrm{C}, \mathrm{P}, \mathrm{Cl})$ while keeping the TZ2P basis sets for $\mathrm{Si}, \mathrm{Ge}, \mathrm{Sn}$ and $\mathrm{Pd}$. The gauge-including atomic orbitals (GIAO) ${ }^{39,40}$ were employed to ensure origin independence for all the absolute shielding constant calculations performed in both the ADF and ReSpect program packages. The solvent effects were predicted using the conductor-like screening model $(\mathrm{COSMO})^{41}$ together with benzene as a solvent for the molecules of $\mathrm{Si}, \mathrm{Ge}, \mathrm{Sn}$ and $\mathrm{Pb}$, whereas acetonitrile solvent was used for the $\mathrm{Pd}$ and $\mathrm{Pt}$ complexes, in both cases similar to the solvents used in the experimental measurements. The following nuclear g-factors were used wherever required: 5.58569 for ${ }^{1} \mathrm{H}, 1.40482$ for ${ }^{13} \mathrm{C},-1.11058$ for ${ }^{29} \mathrm{Si},-0.19544$ for ${ }^{73} \mathrm{Ge},-2.09456$ for ${ }^{119} \mathrm{Sn}$, and 1.18517 for ${ }^{207} \mathrm{~Pb}$; all taken from the IUPAC Green Book. ${ }^{42}$ The reference compounds used for the calculations of the chemical shifts are: $\mathrm{SiMe}_{4}$ for ${ }^{13} \mathrm{C}$ and ${ }^{29} \mathrm{Si}, \mathrm{GeMe}_{4}$ for ${ }^{73} \mathrm{Ge}, \mathrm{SnMe}_{4}$ for ${ }^{119} \mathrm{Sn}$ and $\mathrm{PbMe}_{4}$ for ${ }^{207} \mathrm{~Pb}$. The geometries of the 12 molecules considered in the present study are shown in Figure 2.

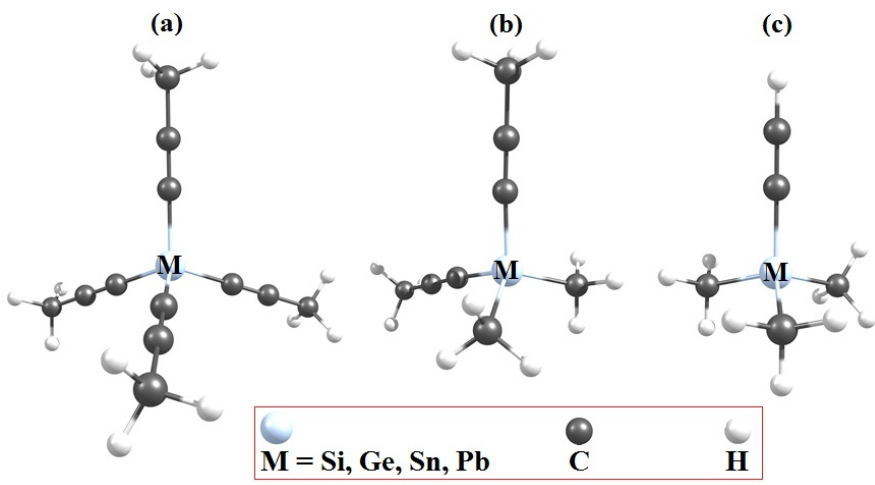

FIG. 2. The geometry of the $\mathrm{X}(\mathrm{CCMe})_{4}$ (a), $\mathrm{Me}_{2} \mathrm{X}(\mathrm{CCMe})_{2}$ (b) and $\mathrm{Me}_{3} \mathrm{XCCH}(\mathrm{c})(\mathrm{X}=\mathrm{Si}, \mathrm{Ge}, \mathrm{Sn}$ and $\mathrm{Pb})$ molecules.

\section{RESULTS AND DISCUSSION}

\section{A. Chemical Shifts}

The chemical shifts of the carbon atoms bonded to the $\mathrm{X}$-atoms $\left(\mathrm{X}={ }^{29} \mathrm{Si},{ }^{73} \mathrm{Ge},{ }^{119} \mathrm{Sn},{ }^{207} \mathrm{~Pb}\right)$ are presented in Table I. Unsurprisingly, the relativistic effects on the chemical shifts of the carbon atoms increase as the Xatoms become heavier (heavy atom effects on the light atoms, HALA ${ }^{43,44}$ ). This is more pronounced for the $\mathrm{sp}^{3}$ hybridized carbon atoms than the sp hybridized ones. For example, the net relativistic correction for the sp hybridized carbon atom attached to lead in $\mathrm{Me}_{2} \mathrm{~Pb}(\mathrm{CCMe})_{2}$ is $9.71 \mathrm{ppm}$, whereas it is $25.60 \mathrm{ppm}$ for the methyl carbon atom.

Comparing the scalar and spin-orbit contributions of the carbon atoms shows that in few cases the former is dominant and able to reproduce major parts of the relativistic effects, see Table I. For instance, $\Delta \mathrm{SC}$ of the carbon atom bonded to tin in $\mathrm{Sn}(\mathrm{CCMe})_{4}$ is $-14.84 \mathrm{ppm}$, whereas $\Delta \mathrm{SO}$ is $3.53 \mathrm{ppm}$. In most cases, the two contributions cancel each other. For instance, the scalar relativistic contribution to the chemical shift of the car- bon atom bonded to lead in $\mathrm{Pb}(\mathrm{CCMe})_{4}$ is $-16.11 \mathrm{ppm}$, whereas that of the spin-orbit contribution is $13.45 \mathrm{ppm}$, leaving a net relativistic correction of $-2.66 \mathrm{ppm}$. The $\Delta \mathrm{SO}$ contribution to the chemical shifts of the methyl carbon atoms attached to lead in $\mathrm{Me}_{2} \mathrm{~Pb}(\mathrm{CCMe})_{2}$ is $8.1 \%$ and the remaining $91.9 \%$ is the scalar contribution, whereas they are $0.40 \%$ and $99.6 \%$, respectively, in $\mathrm{Me}_{3} \mathrm{PbCCH}$. The comparison of the results obtained using dyall-cvtz and dyall-cvqz basis sets shows that the dyall-cvtz basis set gives converged results. Considering the size of the basis sets, the results obtained from the DKS/PBE0/dyall-cvqz calculations should be the most accurate chemical shifts for all molecules. Benchmarking the calculated chemical shifts obtained using the different methods listed in Table I with the DKS/PBE0/dyallcvqz results show that, in most cases, the PBE functional underestimates the ${ }^{13} \mathrm{C}$ chemical shifts. This is true also for the SO-ZORA/PBE0 calculated results.

The chemical shifts of the X-atoms $\left(\mathrm{X}={ }^{29} \mathrm{Si},{ }^{73} \mathrm{Ge}\right.$, $\left.{ }^{119} \mathrm{Sn},{ }^{207} \mathrm{~Pb}\right)$ are listed in Table II. The non-relativistic and relativistic results obtained using the PBE0 functional are close to each other for the light atoms, whereas the differences increase as the atoms become heavier. For instance, the ${ }^{29} \mathrm{Si}$ chemical shift in $\mathrm{Si}(\mathrm{CCMe})_{4}$ calculated using NR/PBE0/dyall-cvtz is $-102.67 \mathrm{ppm}$ and -102.75 ppm using DKS/PBE0/dyall-cvtz, a change by only $0.08 \%$. These chemical shifts for ${ }^{207} \mathrm{~Pb}$ in $\mathrm{Pb}(\mathrm{CCMe})_{4}$ respectively are $-621.62 \mathrm{ppm}$ and $-780.35 \mathrm{ppm}$, a change by $20.30 \%$. Comparing the PBE and PBE0 calculated chemical shifts of the $\mathrm{X}$ atoms shows that the magnitude of the chemical shifts obtained using the former functional are overestimated. For example, the chemical shift of tin in $\mathrm{Sn}(\mathrm{CCMe})_{4}$ obtained using PBE is $-474.83 \mathrm{ppm}$, whereas $-397.00 \mathrm{ppm}$ using the PBE0 functional, see Table II.

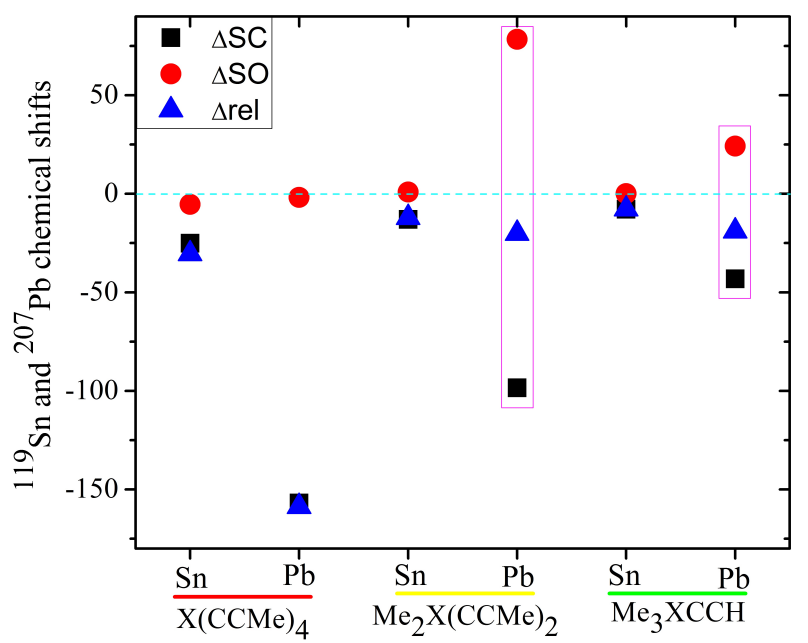

FIG. 3. Comparison of scalar $(\Delta \mathrm{SC})$ and spin-orbit $(\Delta \mathrm{SO})$ relativistic contributions with the total relativistic corrections $\left(\Delta\right.$ rel) of ${ }^{119} \mathrm{Sn}$ and ${ }^{207} \mathrm{~Pb}$ chemical shifts.

The spin-orbit contributions to the chemical shifts of the $\mathrm{X}$-atoms in $\mathrm{X}(\mathrm{CCMe})_{4}$ molecules are small compared to the scalar contributions. However, in the other two groups of molecules, they largely cancel each other. For example, $\Delta \mathrm{SC}$ of lead in $\mathrm{Me}_{2} \mathrm{~Pb}(\mathrm{CCMe})_{2}$ is $-98.50 \mathrm{ppm}$ 
TABLE I. ${ }^{13} \mathrm{C}$ chemical shifts (in ppm) of atoms bonded to the $\mathrm{X}$ atoms (X $\left.={ }^{29} \mathrm{Si},{ }^{73} \mathrm{Ge},{ }^{119} \mathrm{Sn},{ }^{207} \mathrm{~Pb}\right)$ calculated using different Hamiltonians, functionals and basis sets. ${ }^{a}$

\begin{tabular}{|c|c|c|c|c|c|c|c|c|c|}
\hline \multirow[b]{3}{*}{$\mathrm{XC}$} & \multirow{3}{*}{$\begin{array}{r}\text { NR } \\
\text { PBE0 } \\
\text { cvtz }\end{array}$} & \multirow{3}{*}{$\begin{array}{r}\mathrm{ZORA}^{b} \\
\text { PBE0 } \\
\text { TZ2P }\end{array}$} & \multirow{3}{*}{$\begin{array}{r}\mathrm{SC}^{c} \\
\mathrm{PBE} 0 \\
\text { cvtz }\end{array}$} & \multicolumn{3}{|c|}{ DKS } & \multirow{3}{*}{$\begin{array}{r}\Delta \mathrm{SC}^{d} \\
\mathrm{PBE} 0 \\
\text { cvtz }\end{array}$} & \multirow{3}{*}{$\begin{array}{r}\Delta \mathrm{SO}^{e} \\
\mathrm{PBE} 0 \\
\text { cvtz }\end{array}$} & \multirow{3}{*}{$\begin{array}{l}\Delta \text { rel }^{f} \\
\text { PBE0 } \\
\text { cvtz }\end{array}$} \\
\hline & & & & $\mathrm{PBE}$ & PBE0 & PBE0 & & & \\
\hline & & & & cvtz & cvtz & cvqz & & & \\
\hline & \multicolumn{9}{|c|}{$\mathrm{X}(\mathrm{CCMe})_{4}$} \\
\hline$\overline{\mathrm{Si} C \mathrm{C}}$ & 91.88 & 86.77 & 91.53 & 85.21 & 91.97 & 87.80 & -0.35 & 0.44 & $\overline{0.09}$ \\
\hline $\mathrm{Ge} C \mathrm{C}$ & 87.89 & 86.41 & 89.03 & 84.77 & 89.03 & 85.76 & 1.14 & 0.00 & 1.14 \\
\hline $\mathrm{Sn} C \mathrm{C}$ & 101.45 & 88.15 & 86.61 & 84.92 & 90.14 & 85.38 & -14.84 & 3.53 & -11.31 \\
\hline \multirow[t]{2}{*}{$\mathrm{PbCC}$} & 104.47 & 99.32 & 88.36 & 98.86 & 101.81 & 95.91 & -16.11 & 13.45 & -2.66 \\
\hline & \multicolumn{9}{|c|}{$\mathrm{Me}_{2} \mathrm{X}(\mathrm{CCMe})_{2}$} \\
\hline$\overline{\mathrm{Si} C \mathrm{C}}$ & 95.41 & 89.32 & 95.17 & 87.70 & 95.43 & 94.52 & -0.24 & 0.26 & 0.02 \\
\hline $\mathrm{Si} C \mathrm{H}_{3}$ & 2.42 & 2.01 & 2.44 & 2.12 & 2.51 & 1.79 & 0.02 & 0.07 & 0.09 \\
\hline $\mathrm{Ge} C \mathrm{C}$ & 95.90 & 91.06 & 96.95 & 89.24 & 95.94 & 94.71 & 1.05 & -1.01 & 0.04 \\
\hline $\mathrm{Ge}_{\mathrm{CH}} \mathrm{H}_{3}$ & 0.50 & 3.43 & 2.58 & 4.51 & 2.29 & 2.69 & 2.08 & -0.29 & 1.79 \\
\hline $\mathrm{Sn} C \mathrm{C}$ & 90.14 & 90.62 & 91.52 & 87.34 & 92.51 & 91.55 & 1.38 & 0.99 & 2.37 \\
\hline $\mathrm{Sn} C \mathrm{H}_{3}$ & -10.76 & -4.25 & -5.35 & -3.82 & -5.34 & -5.40 & 5.41 & 0.01 & 5.42 \\
\hline $\mathrm{PbCC}$ & 93.46 & 108.94 & 103.76 & 102.23 & 103.17 & 101.14 & 10.30 & -0.59 & 9.71 \\
\hline \multirow[t]{2}{*}{$\mathrm{PbCH}_{3}$} & -18.08 & 8.55 & 5.45 & 12.54 & 7.52 & 8.03 & 23.53 & 2.07 & 25.60 \\
\hline & \multicolumn{9}{|c|}{$\mathrm{Me}_{3} \mathrm{XCCH}$} \\
\hline$\overline{\mathrm{Si} C \mathrm{C}}$ & 100.97 & 96.62 & 100.88 & 96.38 & 101.02 & 100.12 & -0.09 & 0.14 & $\overline{0.05}$ \\
\hline $\mathrm{Si}_{\mathrm{CH}}$ & -2.46 & -1.81 & -2.40 & -0.40 & -2.37 & 0.29 & 0.06 & 0.03 & 0.09 \\
\hline $\mathrm{Ge} C \mathrm{C}$ & 102.37 & 98.58 & 103.34 & 97.41 & 101.63 & 99.31 & 0.97 & -1.71 & -0.74 \\
\hline $\mathrm{Ge}_{\mathrm{CH}} \mathrm{H}_{3}$ & -2.14 & 0.38 & -0.19 & 2.51 & -0.73 & 0.59 & 1.95 & -0.54 & 1.41 \\
\hline $\mathrm{Sn} C \mathrm{C}$ & 100.87 & 99.62 & 102.50 & 97.14 & 100.98 & 100.04 & 1.63 & -1.52 & 0.11 \\
\hline $\mathrm{SnCH}$ & -9.29 & -3.30 & -3.83 & -2.84 & -4.58 & -4.77 & 5.46 & -0.75 & 4.71 \\
\hline $\mathrm{PbCC}$ & 101.84 & 105.64 & 109.06 & 104.91 & 105.53 & 104.20 & 7.22 & -3.53 & 3.69 \\
\hline $\mathrm{PbCH}_{3}$ & -14.65 & 7.50 & 6.69 & 9.77 & 6.61 & 6.38 & 21.34 & -0.08 & 21.26 \\
\hline
\end{tabular}

${ }^{a}$ For carbon atoms in similar chemical environments, the average chemical shifts are reported; cvtz/cvqz stands for the Dyall-cvtz/Dyall-cvqz basis sets.

${ }^{b}$ ZORA stands for the SO-ZORA results calculated using the ADF program package.

${ }^{c} \mathrm{SC}$ stands for the scalar relativistic results calculated using the ReSpect program package by scaling the spin-orbit contribution to zero.

${ }^{d} \Delta \mathrm{SC}$ is scalar relativistic contribution obtained from the difference between SC/PBE0/dyall-cvtz and NR/PBE0/dyall-cvtz results.

e $\Delta \mathrm{SO}$ is the spin-orbit contribution obtained from the difference between the DKS/PBE0/dyall-cvtz and SC/PBE0/dyall-cvtz results.

${ }^{f} \Delta$ rel is the relativistic correction obtained from the difference between the DKS/PBE0/dyall-cvtz and NR/PBE0/dyall-cvtz results.

TABLE II. ${ }^{29} \mathrm{Si},{ }^{73} \mathrm{Ge},{ }^{119} \mathrm{Sn}$ and ${ }^{207} \mathrm{~Pb}$ chemical shifts (in ppm) calculated using different Hamiltonians, functionals and basis sets.

\begin{tabular}{|c|c|c|c|c|c|c|c|c|c|}
\hline \multirow[b]{3}{*}{$\mathrm{X}$} & \multirow{3}{*}{$\begin{array}{r}\mathrm{NR} \\
\mathrm{PBE} 0 \\
\text { cvtz }\end{array}$} & \multirow{3}{*}{$\begin{array}{r}\mathrm{ZORA}^{a} \\
\mathrm{PBE} 0 \\
\mathrm{TZ} 2 \mathrm{P}\end{array}$} & \multirow{3}{*}{$\begin{array}{r}\mathrm{SC}^{b} \\
\mathrm{PBE0} \\
\text { cvtz }\end{array}$} & \multicolumn{3}{|c|}{ DKS } & \multirow{3}{*}{$\begin{array}{r}\Delta \mathrm{SC}^{c} \\
\mathrm{PBE} 0 \\
\text { cvtz }\end{array}$} & \multirow{3}{*}{$\begin{array}{r}\Delta \mathrm{SO}^{d} \\
\mathrm{PBE} 0 \\
\mathrm{cvtz}\end{array}$} & \multirow{3}{*}{$\begin{array}{r}\Delta \text { rel }^{e} \\
\text { PBE0 } \\
\text { cvtz }\end{array}$} \\
\hline & & & & $\mathrm{PBE}$ & PBE0 & PBE0 & & & \\
\hline & & & & cvtz & cvtz & cvqz & & & \\
\hline & \multicolumn{9}{|c|}{$\mathrm{X}(\mathrm{CCMe})_{4}$} \\
\hline $\mathrm{Si}$ & -102.67 & -102.47 & -103.35 & -116.50 & -102.75 & -104.87 & -0.68 & 0.60 & -0.08 \\
\hline $\mathrm{Ge}$ & -177.10 & -219.05 & -179.18 & -221.89 & -178.36 & -180.32 & -2.08 & 0.82 & -1.26 \\
\hline $\mathrm{Sn}$ & -366.51 & -460.32 & -391.64 & -474.83 & -397.00 & -404.47 & -25.13 & -5.36 & -30.49 \\
\hline $\mathrm{Pb}$ & -621.62 & -1107.99 & -778.56 & -1023.65 & -780.35 & -788.67 & -156.94 & -1.79 & -158.73 \\
\hline & \multicolumn{9}{|c|}{$\mathrm{Me}_{2} \mathrm{X}(\mathrm{CCMe})_{2}$} \\
\hline $\mathrm{Si}$ & -40.85 & -44.96 & -41.04 & -52.81 & -40.74 & -43.56 & -0.19 & 0.30 & 0.11 \\
\hline $\mathrm{Ge}$ & -78.68 & -111.32 & -79.55 & -112.76 & -79.24 & -83.40 & -0.87 & 0.31 & -0.56 \\
\hline $\mathrm{Sn}$ & -167.18 & -209.78 & -180.17 & -224.44 & -179.25 & -186.89 & -12.99 & 0.92 & -12.07 \\
\hline \multirow[t]{2}{*}{$\mathrm{Pb}$} & -314.48 & -556.08 & -412.98 & -469.85 & -334.60 & -343.62 & -98.50 & 78.38 & -20.12 \\
\hline & \multicolumn{9}{|c|}{$\mathrm{Me}_{3} \mathrm{XCCH}$} \\
\hline $\mathrm{Si}$ & -11.40 & -20.01 & -11.45 & -23.46 & -11.29 & -9.95 & -0.05 & 0.16 & 0.11 \\
\hline $\mathrm{Ge}$ & -11.56 & -54.25 & -10.81 & -52.94 & -10.88 & -9.63 & 0.75 & -0.07 & 0.68 \\
\hline $\mathrm{Sn}$ & -104.01 & -131.34 & -111.84 & -133.91 & -111.76 & -109.40 & -7.83 & 0.08 & -7.75 \\
\hline $\mathrm{Pb}$ & -176.23 & -298.81 & -219.41 & -244.80 & -195.18 & -184.51 & -43.18 & 24.23 & -18.95 \\
\hline
\end{tabular}

${ }^{a}$ ZORA stands for the SO-ZORA results calculated using the ADF program package.

${ }^{b} \mathrm{SC}$ stands for the scalar relativistic results calculated using the ReSpect program package by scaling the spin-orbit contribution to zero.

${ }^{c} \triangle \mathrm{SC}$ is scalar relativistic contribution obtained from the difference between SC/PBE0/dyall-cvtz and NR/PBE0/dyall-cvtz results.

${ }^{d} \Delta \mathrm{SO}$ is the spin-orbit contribution obtained from the difference between the DKS/PBE0/dyall-cvtz and SC/PBE0/dyall-cvtz results.

${ }^{e} \Delta \mathrm{rel}$ is the relativistic correction obtained from the difference between the DKS/PBE0/dyall-cvtz and NR/PBE0/dyall-cvtz results. 
whereas $\Delta \mathrm{SO}$ is $78.38 \mathrm{ppm}$, making a net $\Delta$ rel of -20.12 ppm. Figure 3 compares the two contributions with the net relativistic corrections for the tin and lead nuclei. One can see that the net relativistic correction and the scalar contribution are in most cases close to each other. This is more pronounced for the lead atoms. For example, $\Delta \mathrm{SC}$ of lead in $\mathrm{Pb}(\mathrm{CCMe})_{4}$ is $98.9 \%$ whereas $\Delta \mathrm{SO}$ is only $1.1 \%$ of $\Delta$ rel.

\section{B. Indirect Spin-Spin Coupling Constants}

The calculated ${ }^{1} J_{\mathrm{XC}}\left(\mathrm{X}={ }^{29} \mathrm{Si},{ }^{73} \mathrm{Ge},{ }^{119} \mathrm{Sn},{ }^{207} \mathrm{~Pb}\right)$ indirect spin-spin coupling constants together with available experimental values are presented in Table III. For the coupling constants involving the heavy atoms, the relativistic corrections are of the same order of magnitude compared to the non-relativistically calculated values (see for instance the ${ }^{1} J_{\mathrm{PbC}}$ values in Table III). The calculated ${ }^{1} J_{\mathrm{XC}}$ values show that the spin-orbit contributions to the coupling constants of all molecules are small compared to the scalar contributions. For instance, the $\Delta \mathrm{SO}$ contribution of the ${ }^{1} J_{\mathrm{SnC}}$ in $\mathrm{Sn}(\mathrm{CCMe})_{4}$ is only $7.57 \%$ of the total $-266.59 \mathrm{~Hz}$ relativistic correction, whereas $\Delta \mathrm{SC}$ contributes $92.43 \%$. These contributions are $-10.52 \%$ and $110.52 \%$ of the total $858.07 \mathrm{~Hz}$, respectively, for ${ }^{1} J_{\mathrm{PbC}}$ in $\mathrm{Pb}(\mathrm{CCMe})_{4}$. The scalar contribution for the ${ }^{1} J_{\mathrm{PbC}}$ in $\mathrm{Pb}(\mathrm{CCMe})_{4}$ is $948.35 \mathrm{~Hz}$, whereas that of the spin-orbit contribution is $-90.28 \mathrm{~Hz}$. For the same coupling constant, the net relativistic correction is 858.07 $\mathrm{Hz}$, which is close to the non-relativistic value of 906.60 $\mathrm{Hz}$. Overall, the scalar contributions are dominant over the spin-orbit contributions, which could be due to the low s character of the $\mathrm{X}-\mathrm{C}$ bonds, in agreement with previous theoretical studies..$^{25,26,46}$ Table III also shows that the net relativistic correction in most of the molecules is negative, reducing the coupling constants. Even though the $\Delta \mathrm{SO}$ contributions are small, it is important to consider both the scalar and spin-orbit contributions in order to get accurate results.

The calculated ${ }^{n} J_{\mathrm{XH}}(\mathrm{n}=2-4)$ using different methods together with available experimental values are listed in Table IV. The relativistic effects increase when going from $\mathrm{Si}$ to $\mathrm{Pb}$. Similar to the previous discussions, the scalar contributions are dominant over the spin-orbit contributions of the ${ }^{n} J_{\mathrm{XH}}$ results. In most cases, the two contributions cancel each other and the largest cancellations between the two contributions is observed for the ${ }^{2} J_{\mathrm{Sn}, \mathrm{CH}_{3}}$ of $\mathrm{Me}_{2} \mathrm{Sn}(\mathrm{CCMe})_{2}(\Delta \mathrm{SC}$ is $21.33 \mathrm{~Hz}$ and $\Delta \mathrm{SO}$ is $-20.82 \mathrm{~Hz}$, whereas $\Delta$ rel is only $0.51 \mathrm{~Hz})$. Previous studies of ${ }^{1} J_{\mathrm{XH}}$ of $\mathrm{XH}_{4}$ molecules $\left(\mathrm{X}={ }^{29} \mathrm{Si},{ }^{73} \mathrm{Ge}\right.$, $\left.{ }^{119} \mathrm{Sn},{ }^{207} \mathrm{~Pb}\right){ }^{25}$ showed that the total relativistic correction to the spin-spin coupling constants is positive. In the present study, the net relativistic corrections in most of the molecules is negative which tend to reduce the coupling constants.

In Table $\mathrm{V}$, the calculated and available experimental ${ }^{n} J_{\mathrm{XC}}(\mathrm{n}=2,3)$ are listed. The relativistic corrections to the coupling constants through two bonds are larger than those through three bonds. For the ${ }^{n} J_{\mathrm{PbC}}$ coupling constants, in some cases, the relativistic corrections are close to the experimental spin-spin coupling constants. For example, the non-relativistic ${ }^{3} J_{\mathrm{Pb}, \mathrm{CH}_{3}}$ in $\mathrm{Pb}(\mathrm{CCMe})_{4}$ is $17.59 \mathrm{~Hz}$, and $\Delta$ rel is $22.42 \mathrm{~Hz}$, whereas the experimental value is $30.5 \mathrm{~Hz}$.

\section{Comparison with Experiment}

Experimental chemical shifts for all the molecules studied in this paper are not available for comparison. However, there are experimental spin-spin coupling constants for some of the molecules. Therefore, in this section, the calculated indirect spin-spin coupling constants using different methods are compared with available experimental values. The DKS/PBE0 calculated ${ }^{1} J_{\mathrm{XC}}$ indirect spin-spin coupling constants satisfactorily reproduce the corresponding experimental values (see Table III). For instance, the DKS/PBE calculated ${ }^{1} J_{\mathrm{SnC}}$ in $\mathrm{Sn}(\mathrm{CCMe})_{4}$ is $-1033.64 \mathrm{~Hz}$ (underestimated by $11.5 \%$ ) whereas it is $-1223.66 \mathrm{~Hz}$ using DKS/PBE0 (overestimated by $4.8 \%$ ). The latter result is in good agreement with the experimental value of $-1168.0 \mathrm{~Hz}$. The only exception in this aspect is the ${ }^{1} J_{\mathrm{PbC}}$ in $\mathrm{Me}_{2} \mathrm{~Pb}(\mathrm{CCMe})_{2}$ which is not reproduced by any of the methods. The SO-ZORA calculations performed in benzene as solvent (the solvent used for the experimental measurements, see Tables Sup I - III of the Supplementary Material) showed a solvent effect correction of $-137.89 \mathrm{~Hz}$; adding this to $-3.40 \mathrm{~Hz}$, obtained from DKS/PBE0/dyall-cvtz calculation, gives $-141.29 \mathrm{~Hz}$ which is still far from the experimental value of $208 \mathrm{~Hz}$. This could happen if the response of the spin-density due to the Fermi-contact operator on $\mathrm{Pb}$ changes its sign (crosses the zero plane). In addition, rovibrational effects could be very important for this specific coupling constant. To assess this, the ${ }^{1} J_{\mathrm{PbC}}$ coupling constants were calculated by varying the $\mathrm{Pb}-\mathrm{C}$ bond length. The results are plotted in Figure 4.

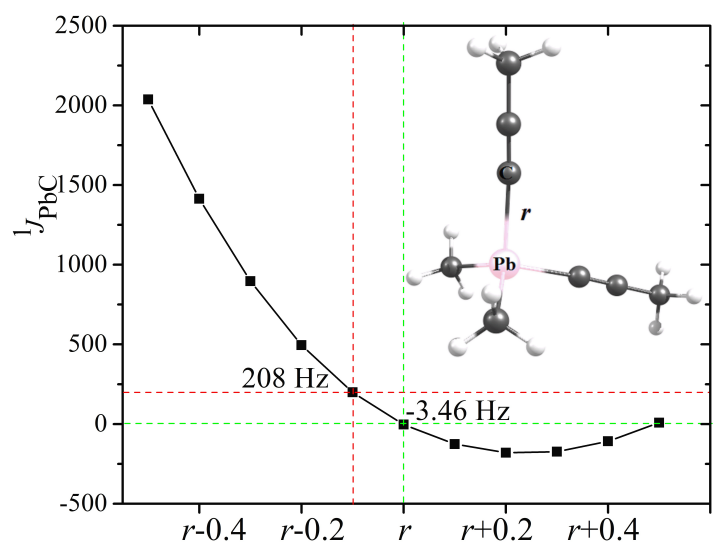

FIG. 4. Bond length dependence of ${ }^{1} J_{\mathrm{PbC}}$ spin-spin coupling constant of $\mathrm{Me}_{2} \mathrm{~Pb}(\mathrm{CCMe})_{2}$ calculated using SOZORA/PBE0/JCPL.

Figure 4 shows a strong dependence of the coupling constant on the length of the $\mathrm{Pb}-\mathrm{C}$ bond. The results obtained after decreasing the $\mathrm{Pb}-\mathrm{C}$ bond length by approximately $0.1 \AA(r-0.1)$ is very close to the experimental value, see the crossing point of the red lines. It is ex- 
TABLE III. ${ }^{1} J_{\mathrm{XC}}\left(\mathrm{X}={ }^{29} \mathrm{Si},{ }^{73} \mathrm{Ge},{ }^{119} \mathrm{Sn},{ }^{207} \mathrm{~Pb}\right)$ indirect spin-spin coupling constants (in Hz) calculated using different Hamiltonians, functionals and basis sets together with available experimental values. ${ }^{a}$

\begin{tabular}{|c|c|c|c|c|c|c|c|c|c|c|}
\hline \multirow[b]{3}{*}{${ }^{1} J_{\mathrm{XC}}$} & \multirow{3}{*}{$\begin{array}{r}\text { NR } \\
\text { PBE0 } \\
\text { cvtz }\end{array}$} & \multirow{3}{*}{$\begin{array}{r}\text { ZORA }^{b} \\
\text { PBE0 } \\
\text { TZ2P }\end{array}$} & \multirow{3}{*}{$\begin{array}{r}\mathrm{SC}^{c} \\
\mathrm{PBE} 0 \\
\text { cvtz }\end{array}$} & \multicolumn{3}{|c|}{ DKS } & \multirow{3}{*}{$\begin{array}{r}\mathrm{SC}^{d} \\
\mathrm{PBE} 0 \\
\text { cvtz }\end{array}$} & \multirow{3}{*}{$\begin{array}{r}\mathrm{SO}^{e} \\
\mathrm{PBE} 0 \\
\text { cvtz }\end{array}$} & \multirow{3}{*}{$\begin{array}{r}\text { rel }^{f} \\
\text { PBE0 } \\
\text { cvtz }\end{array}$} & \multirow[t]{3}{*}{ Exp. ${ }^{45}$} \\
\hline & & & & $\mathrm{PBE}$ & PBE0 & $\overline{\mathrm{PBE} 0}$ & & & & \\
\hline & & & & cvtz & cvtz & cvqz & & & & \\
\hline & \multicolumn{10}{|c|}{$\mathrm{X}(\mathrm{CCMe})_{4}$} \\
\hline${ }^{1} J_{\mathrm{SiC} \equiv}$ & -129.74 & -116.20 & -132.50 & -121.05 & -132.32 & -133.48 & -2.76 & 0.18 & -2.58 & - \\
\hline${ }^{1} J_{\mathrm{GeC} \equiv}$ & -55.28 & -49.48 & -60.97 & -52.10 & -60.52 & -60.85 & -5.69 & 0.45 & -5.24 & - \\
\hline${ }^{1} J_{\mathrm{SnC} \equiv}$ & -957.07 & -1073.64 & -1243.83 & -1033.64 & -1223.66 & -1229.39 & -286.76 & 20.17 & -266.59 & -1168.0 \\
\hline${ }^{1} J_{\mathrm{PbC} \equiv}$ & 906.60 & 1505.25 & 1854.95 & 1340.32 & 1764.67 & 1776.91 & 948.35 & -90.28 & 858.07 & 1624.5 \\
\hline & \multicolumn{10}{|c|}{$\mathrm{Me}_{2} \mathrm{X}(\mathrm{CCMe})_{2}$} \\
\hline${ }^{1} J_{\mathrm{SiCH}_{3}}$ & -55.63 & -46.08 & -56.65 & -46.96 & -56.53 & -57.13 & -1.02 & 0.12 & -0.90 & - \\
\hline${ }^{1} J_{\mathrm{SiC} \equiv}$ & -99.16 & -87.23 & -100.71 & -90.31 & -100.56 & -101.42 & -1.55 & 0.15 & -1.40 & - \\
\hline${ }^{1} \mathrm{~J}_{\mathrm{GeCH}_{3}}$ & -20.45 & -16.94 & -21.93 & -15.36 & -22.29 & -21.93 & -1.48 & -0.36 & -1.84 & - \\
\hline${ }^{1} J_{\mathrm{GeC} \equiv}$ & -35.26 & -30.13 & -36.69 & -28.77 & -36.27 & -36.46 & -1.43 & 0.42 & -1.01 & - \\
\hline${ }^{1} \mathrm{~J}_{\mathrm{SnCH}_{3}}$ & -366.31 & -363.14 & -445.99 & -293.47 & -440.39 & -443.68 & -79.68 & 5.60 & -74.08 & -496.2 \\
\hline${ }^{1} J_{\mathrm{SnC}} \equiv$ & -580.90 & -550.44 & -632.24 & -456.94 & -613.09 & -616.39 & -51.34 & 19.15 & -32.19 & -654.6 \\
\hline${ }^{1} \mathrm{~J}_{\mathrm{PbCH}_{3}}$ & 320.11 & 373.73 & 489.80 & 219.48 & 491.32 & 498.24 & 169.69 & 1.52 & 171.21 & 574.3 \\
\hline${ }^{1} J_{\mathrm{PbC} \equiv}$ & 467.49 & 55.89 & 66.94 & -172.64 & -3.40 & -5.67 & -400.55 & -70.34 & -470.89 & 208.0 \\
\hline & \multicolumn{10}{|c|}{$\mathrm{Me}_{3} \mathrm{XCCH}$} \\
\hline${ }^{1} J_{\mathrm{SiCH}_{3}}$ & -49.93 & -42.04 & -50.72 & -41.17 & -51.15 & -51.13 & -0.79 & -0.43 & -1.22 & -55.1 \\
\hline${ }^{1} J_{\mathrm{SiC}} \equiv$ & -77.15 & -68.09 & -78.04 & -68.12 & -77.91 & -78.57 & -0.89 & 0.13 & -0.76 & -79.4 \\
\hline${ }^{1} J_{\mathrm{GeCH}_{3}}$ & -17.01 & -13.86 & -17.79 & -11.51 & -17.66 & -16.77 & -0.78 & 0.13 & -0.65 & - \\
\hline${ }^{1} J_{\mathrm{GeC}} \equiv$ & -23.98 & -19.61 & -23.63 & -16.30 & -23.25 & -23.35 & 0.35 & 0.38 & 0.73 & - \\
\hline${ }^{1} J_{\mathrm{SnCH}_{3}}$ & -302.24 & -279.85 & -344.31 & -201.25 & -339.18 & -341.78 & -42.07 & 5.13 & -36.94 & -403.5 \\
\hline${ }^{1} J_{\mathrm{SnC}} \equiv$ & -379.21 & -298.59 & -343.61 & -188.91 & -326.78 & -328.16 & 35.60 & 16.83 & 52.43 & -415.5 \\
\hline${ }^{1} J_{\mathrm{PbCH}_{3}}$ & 255.64 & 199.93 & 259.64 & 39.03 & 264.83 & 266.79 & 4.00 & 5.19 & 9.19 & - \\
\hline${ }^{1} J_{\mathrm{PbC}} \equiv$ & 279.51 & -321.52 & -368.01 & -554.57 & -440.91 & -445.76 & -647.52 & -72.90 & -720.42 & - \\
\hline
\end{tabular}

${ }^{a}$ Average $J$ values are reported for atoms in similar chemical environments.
${ }^{b}$ ZORA stands for the SO-ZORA results calculated using the ADF program package.

${ }^{c} \mathrm{SC}$ stands for the scalar relativistic results calculated using the ReSpect program package by scaling the spin-orbit contribution to zero. ${ }^{d} \triangle \mathrm{SC}$ is scalar relativistic contribution obtained from the difference between SC/PBE0/dyall-cvtz and NR/PBE0/dyall-cvtz results. e $\triangle \mathrm{SO}$ is the spin-orbit contribution obtained from the difference between the DKS/PBE0/dyall-cvtz and SC/PBE0/dyall-cvtz results.

${ }^{f} \Delta$ rel is the relativistic correction obtained from the difference between the DKS/PBE0/dyall-cvtz and NR/PBE0/dyall-cvtz results.

tremely difficult to calculate the rovibrational corrections for a molecule with many geometrical constraints and the disagreement between this calculated and experimental ${ }^{1} J_{\mathrm{PbC}}$ spin-spin coupling constant of $\mathrm{Me}_{2} \mathrm{~Pb}(\mathrm{CCMe})_{2}$ will remain unsolved.

The ${ }^{n} J_{\mathrm{XH}}$ results for the $\mathrm{X}(\mathrm{CCMe})_{4}$ molecules are better reproduced using the PBE functional (see Table IV). For example, the calculated ${ }^{4} J_{\mathrm{Sn}, \mathrm{CH}_{3}}$ in $\mathrm{Sn}(\mathrm{CCMe})_{4}$ using PBE0 is $26.68 \mathrm{~Hz}$, whereas it is $17.57 \mathrm{~Hz}$ using PBE, which is comparable to the experimental value of $17.0 \mathrm{~Hz}$. For the other two sets of molecules, the PBE0 functional satisfactorily reproduced the indirect spin-spin coupling constants. The calculated ${ }^{2} J_{\mathrm{Sn}, \mathrm{CH}_{3}}$ in $\mathrm{Me}_{2} \mathrm{Sn}(\mathrm{CCMe})_{2}$ using $\mathrm{PBE}$ is $56.90 \mathrm{~Hz}$, whereas it is $68.19 \mathrm{~Hz}$ using PBE0, which is very close to the experimental value of $68.8 \mathrm{~Hz}$ (see Table IV).

The non-relativistically calculated results for the spinspin coupling constants involving tin and lead are far from the experimental values (see Figure Sup I of the Supplementary Material). From Figure Sup I, one can also see that the inclusion of only scalar relativistic corrections gives satisfactory results for the molecules studied. However, very accurate results are obtained when using the full four-component relativistic approach, indicating the importance of including both relativistic contributions. The results obtained from SO-ZORA calculations are also not satisfactory compared to the full four- component results. This is mainly due to the approximate nature of the ZORA Hamiltonian and inadequacy of the TZ2P basis sets for the calculation of spin-spin coupling constants. To confirm the latter, additional calculations were performed using the JCPL basis sets (especially designed basis sets, of TZ2P quality and containing additional high-exponent functions for added flexibility to describe the spin density very close to the nuclei, for NMR spin-spin coupling calculations), ${ }^{38,47}$ presented in Table VII for the lead and platinum complexes. The results calculated using TZ2P basis sets for $\mathrm{Si}, \mathrm{Ge}, \mathrm{Sn}$ and $\mathrm{Pd}$ while keeping the JCPL basis sets for the other atoms are presented in Tables Sup V - VIII of the Supplementary Material. Table VII shows that the couplings obtained using the JCPL basis sets are in better agreement with the four-component relativistic results compared to those obtained using SO-ZORA/PBE0/TZ2P. Moreover, the JCPL basis set results are also in better agreement with the experimental spin-spin coupling constants compared to the results obtained with the TZ2P basis sets, especially for the coupling constants through one bond, in agreement with previous theoretical studies. ${ }^{38,47-49}$ However, the results obtained from the calculations performed using TZ2P basis sets for $\mathrm{Si}, \mathrm{Ge}, \mathrm{Sn}$ and Pd while keeping the JCPL basis sets for $\mathrm{H}, \mathrm{C}, \mathrm{P}$ and $\mathrm{Cl}$ are in poor agreement with both the experimental results as well as the four-component results (see Tables 
TABLE IV. ${ }^{n} J_{\mathrm{XH}}\left(\mathrm{X}={ }^{29} \mathrm{Si},{ }^{73} \mathrm{Ge},{ }^{119} \mathrm{Sn},{ }^{207} \mathrm{~Pb}, \mathrm{n}=2-4\right)$ indirect spin-spin coupling constants (in Hz) calculated using different Hamiltonians, functionals and basis sets together with available experimental values. ${ }^{a}$

\begin{tabular}{|c|c|c|c|c|c|c|c|c|c|c|}
\hline \multirow[b]{3}{*}{${ }^{n} J_{\mathrm{XH}}$} & \multirow{3}{*}{$\begin{array}{r}\text { NR } \\
\text { PBE0 } \\
\text { cvtz }\end{array}$} & \multirow{3}{*}{$\begin{array}{r}\mathrm{ZORA}^{b} \\
\text { PBE0 } \\
\text { TZ2P }\end{array}$} & \multirow{3}{*}{$\begin{array}{r}\mathrm{SC}^{c} \\
\mathrm{PBE0} \\
\text { cvtz }\end{array}$} & \multicolumn{3}{|c|}{ DKS } & \multirow{3}{*}{$\begin{array}{r}\mathrm{SC}^{d} \\
\mathrm{PBE} 0 \\
\text { cvtz }\end{array}$} & \multirow{3}{*}{$\begin{array}{r}\mathrm{SO}^{e} \\
\mathrm{PBE} 0 \\
\text { cvtz }\end{array}$} & \multirow{3}{*}{$\begin{array}{r}\text { rel }^{f} \\
\text { PBE0 } \\
\text { cvtz }\end{array}$} & \multirow[t]{3}{*}{ Exp. ${ }^{45}$} \\
\hline & & & & $\mathrm{PBE}$ & PBE0 & $\overline{\mathrm{PBE} 0}$ & & & & \\
\hline & & & & cvtz & cvtz & cvqz & & & & \\
\hline & \multicolumn{10}{|c|}{$\mathrm{X}(\mathrm{CCMe})_{4}$} \\
\hline${ }^{4} J_{\mathrm{Si}, \mathrm{CH}_{3}}$ & 2.69 & 2.05 & 2.75 & 1.86 & 2.74 & 2.78 & 0.06 & -0.01 & 0.05 & - \\
\hline${ }^{4} J_{\mathrm{Ge}, \mathrm{CH}_{3}}$ & 1.27 & 0.99 & 1.43 & 0.95 & 1.42 & 1.43 & 0.16 & -0.01 & 0.15 & - \\
\hline${ }^{4} J_{\mathrm{Sn}, \mathrm{CH}_{3}}$ & 19.67 & 20.26 & 27.32 & 17.57 & 26.68 & 26.93 & 7.65 & -0.64 & 7.01 & 17.0 \\
\hline \multirow{2}{*}{${ }^{4} J_{\mathrm{Pb}, \mathrm{CH}_{3}}$} & -18.08 & -32.79 & -46.29 & -26.46 & -34.14 & -43.72 & -28.21 & 12.15 & -16.06 & -28.0 \\
\hline & \multicolumn{10}{|c|}{$\mathrm{Me}_{2} \mathrm{X}(\mathrm{CCMe})_{2}$} \\
\hline${ }^{2} J_{\mathrm{Si}, \mathrm{CH}_{3}}$ & 6.52 & 5.47 & 6.58 & 4.58 & 6.57 & 6.64 & 0.06 & -0.01 & 0.05 & $\overline{-}$ \\
\hline${ }^{4} J_{\mathrm{Si}, \mathrm{CH}_{3}}$ & 2.47 & 1.81 & 2.52 & 1.65 & 2.51 & 2.54 & 0.05 & -0.01 & 0.04 & - \\
\hline${ }^{2} J_{\mathrm{Ge}, \mathrm{CH}_{3}}$ & 2.89 & 2.27 & 3.58 & 2.26 & 3.53 & 3.55 & 0.69 & -0.05 & 0.64 & - \\
\hline${ }^{4} J_{\mathrm{Ge}, \mathrm{CH}_{3}}$ & 1.06 & 0.78 & 1.16 & 0.72 & 1.14 & 1.15 & 0.10 & -0.02 & 0.08 & - \\
\hline${ }^{2} J_{\mathrm{Sn}, \mathrm{CH}_{3}}$ & 67.68 & 44.70 & 89.01 & 56.90 & 68.19 & 68.83 & 21.33 & -20.82 & 0.51 & 68.8 \\
\hline${ }^{4} J_{\mathrm{Sn}, \mathrm{CH}_{3}}$ & 16.11 & 14.29 & 20.31 & 21.41 & 19.61 & 19.80 & 4.20 & -0.70 & 3.50 & 13.1 \\
\hline${ }^{2} J_{\mathrm{Pb}, \mathrm{CH}_{3}}$ & -65.41 & -62.05 & -129.31 & -60.10 & -119.20 & -120.30 & -63.90 & 10.11 & -53.79 & -100.9 \\
\hline \multirow[t]{2}{*}{${ }^{4} J_{\mathrm{Pb}, \mathrm{CH}_{3}}$} & -13.19 & -12.67 & -17.83 & -6.72 & -15.01 & -15.14 & -4.64 & 2.82 & -1.82 & -13.5 \\
\hline & \multicolumn{10}{|c|}{$\mathrm{Me}_{3} \mathrm{XCCH}$} \\
\hline${ }^{2} J_{\mathrm{Si}, \mathrm{CH}_{3}}$ & 6.53 & 4.97 & 6.59 & 4.49 & 6.58 & 6.77 & 0.06 & -0.01 & 0.05 & 7.0 \\
\hline${ }^{3} J_{\mathrm{Si}, \mathrm{CH}}$ & -4.75 & -3.49 & -4.85 & -3.88 & -4.84 & -4.90 & -0.10 & 0.01 & -0.09 & $(-) 4.0$ \\
\hline${ }^{2} J_{\mathrm{Ge}, \mathrm{CH}_{3}}$ & 2.68 & 2.38 & 2.81 & 1.54 & 2.76 & 2.78 & 0.13 & -0.05 & 0.08 & - \\
\hline${ }^{3} J_{\mathrm{Ge}, \mathrm{CH}}$ & -1.91 & -1.49 & -2.07 & -1.61 & -2.05 & -2.06 & -0.16 & 0.02 & -0.14 & - \\
\hline${ }^{2} J_{\mathrm{Sn}, \mathrm{CH}_{3}}$ & 46.11 & 39.88 & 53.45 & 29.41 & 55.10 & 55.56 & 7.34 & 1.65 & 8.99 & 61.0 \\
\hline${ }^{3} J_{\mathrm{Sn}, \mathrm{CH}}$ & -29.40 & -25.76 & -35.18 & -26.53 & -34.08 & -34.35 & -5.78 & 1.10 & -4.68 & -34.0 \\
\hline${ }^{2} J_{\mathrm{Pb}, \mathrm{CH}_{3}}$ & -51.86 & -44.69 & -73.31 & -17.30 & -63.47 & -53.26 & -21.45 & 9.84 & -11.61 & - \\
\hline${ }^{3} J_{\mathrm{Pb}, \mathrm{CH}}$ & 23.81 & 16.29 & 23.29 & 14.48 & 18.46 & 18.62 & -0.52 & -4.83 & -5.35 & - \\
\hline
\end{tabular}

${ }^{a}$ Average $J$ values are reported for atoms in similar chemical environments.

${ }^{b}$ ZORA stands for the SO-ZORA results calculated using the ADF program package.

${ }^{c}$ SC stands for the scalar relativistic results calculated using the ReSpect program package by scaling the spin-orbit contribution to zero.

${ }^{d} \triangle \mathrm{SC}$ is scalar relativistic contribution obtained from the difference between SC/PBE0/dyall-cvtz and NR/PBE0/dyall-cvtz results.

$e \triangle \mathrm{SO}$ is the spin-orbit contribution obtained from the difference between the DKS/PBE0/dyall-cvtz and SC/PBE0/dyall-cvtz results.

${ }^{f} \Delta$ rel is the relativistic correction obtained from the difference between the DKS/PBE0/dyall-cvtz and NR/PBE0/dyall-cvtz results.

Sup V - VIII of the Supplementary Material).

The correlations between the calculated and experimental results presented in Figure 5 show that the hybrid PBE0 exchange-correlation functional together with the full four-component relativistic approach reproduces the experimental results with an $\mathrm{R}^{2}$ value of 0.983 and standard error of $10.750 \mathrm{~Hz}$, much better than the PBE functional which gave an $\mathrm{R}^{2}$ value of 0.927 and standard deviation of $17.348 \mathrm{~Hz}$.

Previous studies showed that solvent effects play an important role for the accurate prediction of spin-spin coupling constants. ${ }^{50-54}$ The solvent effect corrections obtained from SO-ZORA/PBE0 calculations improved the agreement between the calculated and the experimental results. In most cases, the solvent effects are very considerable for the coupling constants involving tin and lead (see Table Sup I - III of the Supplementary Material; especially those between the sp hybridized carbon atoms and the heavy atoms).

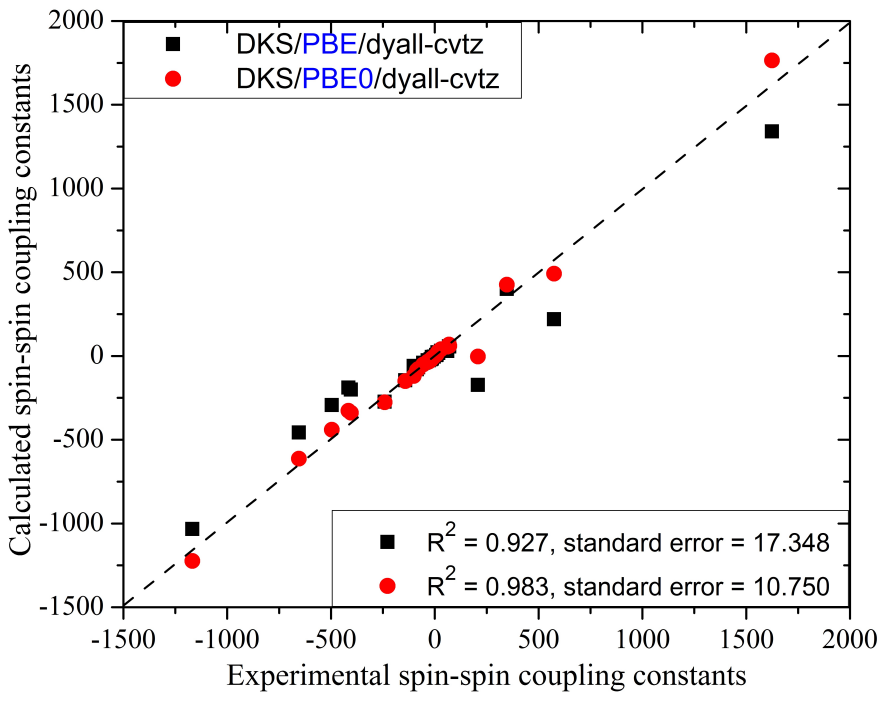

FIG. 5. Correlation between the calculated (DKS/PBE/dyall-cvtz and DKS/PBE0/dyall-cvtz) and available experimental spin-spin coupling constants.

Finally, the four-component relativistic approach was used to calculate the indirect spin-spin coupling constants of two 'large' molecule (both with 110 atoms involving palladium and platinum, see Fig. 1 for the 
TABLE V. ${ }^{n} J_{\mathrm{XC}}\left(\mathrm{X}={ }^{29} \mathrm{Si},{ }^{73} \mathrm{Ge},{ }^{119} \mathrm{Sn},{ }^{207} \mathrm{~Pb}, \mathrm{n}=2,3\right)$ indirect spin-spin coupling constants (in Hz) calculated using different Hamiltonians, functionals and basis sets together with available experimental values. ${ }^{a}$

\begin{tabular}{|c|c|c|c|c|c|c|c|c|c|c|}
\hline \multirow[b]{3}{*}{${ }^{n} J_{\mathrm{XC}}$} & \multirow{3}{*}{$\begin{array}{r}\text { NR } \\
\text { PBE0 } \\
\text { cvtz }\end{array}$} & \multirow{3}{*}{$\begin{array}{r}\mathrm{ZORA}^{b} \\
\text { PBE0 } \\
\text { TZ2P }\end{array}$} & \multirow{3}{*}{$\begin{array}{r}\mathrm{SC}^{c} \\
\mathrm{PBE} 0 \\
\mathrm{cvtz}\end{array}$} & \multicolumn{3}{|c|}{ DKS } & \multirow{3}{*}{$\begin{array}{r}\mathrm{SC}^{d} \\
\mathrm{PBE} 0 \\
\text { cvtz }\end{array}$} & \multirow{3}{*}{$\begin{array}{r}\mathrm{SO}^{e} \\
\mathrm{PBE} 0 \\
\text { cvtz }\end{array}$} & \multirow{3}{*}{$\begin{array}{r}\Delta \text { rel }^{f} \\
\text { PBE0 } \\
\text { cvtz }\end{array}$} & \multirow[t]{3}{*}{ Exp. $^{45}$} \\
\hline & & & & $\overline{\mathrm{PBE}}$ & PBE0 & PBE0 & & & & \\
\hline & & & & cvtz & cvtz & cvqz & & & & \\
\hline & \multicolumn{10}{|c|}{$\mathrm{X}(\mathrm{CCMe})_{4}$} \\
\hline${ }^{2} J_{\mathrm{SiC} \equiv{ }^{13} \mathrm{C}}$ & -28.39 & -27.27 & -29.04 & -29.60 & -29.03 & -29.33 & -0.65 & 0.01 & -0.64 & - \\
\hline${ }^{3} J_{\mathrm{Si}, 13} \mathrm{CH}_{3}$ & -2.57 & -1.94 & -2.63 & -2.13 & -2.63 & -2.65 & -0.06 & 0.00 & -0.06 & - \\
\hline${ }^{2} J_{\mathrm{GeC} \equiv 13 C}$ & -12.26 & -11.89 & -13.57 & -13.50 & -13.53 & -13.64 & -1.31 & 0.04 & -1.27 & - \\
\hline${ }^{3} J_{\mathrm{Ge},{ }^{13} \mathrm{CH}_{3}}$ & -1.16 & -0.89 & -1.30 & -1.01 & -1.29 & -1.30 & -0.14 & 0.01 & -0.13 & - \\
\hline${ }^{2} J_{\mathrm{SnC} \equiv{ }^{13} \mathrm{C}}$ & -213.12 & -254.90 & -277.75 & -272.95 & -276.26 & -278.61 & -64.63 & 1.49 & -63.14 & -241.0 \\
\hline${ }^{3} J_{\mathrm{Sn}, 13} \mathrm{CH}_{3}$ & -19.00 & -18.70 & -25.51 & -19.94 & -25.25 & -25.34 & -6.51 & 0.26 & -6.25 & -19.5 \\
\hline${ }^{2} J_{\mathrm{PbC} \equiv 13 C}$ & 200.02 & 380.35 & 429.84 & 399.48 & 425.36 & 429.67 & 229.82 & -4.48 & 225.34 & 347.4 \\
\hline \multirow[t]{2}{*}{${ }^{3} \mathrm{~J}_{\mathrm{Pb},{ }^{13} \mathrm{CH}_{3}}$} & 17.59 & 28.89 & 40.88 & 30.02 & 40.01 & 40.16 & 23.29 & -0.87 & 22.42 & 30.5 \\
\hline & \multicolumn{10}{|c|}{$\mathrm{Me}_{2} \mathrm{X}(\mathrm{CCMe})_{2}$} \\
\hline${ }^{2} J_{\mathrm{SiC} \equiv{ }^{13} \mathrm{C}}$ & -21.04 & -20.57 & -21.40 & -21.88 & -21.39 & -21.61 & -0.36 & 0.01 & -0.35 & - \\
\hline${ }^{3} J_{\mathrm{Si}, 13} \mathrm{CH}_{3}$ & -2.13 & -1.61 & -2.17 & -1.67 & -2.17 & -2.19 & -0.04 & 0.00 & -0.04 & - \\
\hline${ }^{2} J_{\mathrm{GeC} \equiv 13 \mathrm{C}}$ & -7.83 & -7.48 & -8.23 & -8.06 & -8.19 & -8.25 & -0.40 & 16.42 & 16.02 & - \\
\hline${ }^{3} J_{\mathrm{Ge},{ }^{13} \mathrm{CH}_{3}}$ & -0.86 & -0.60 & -0.93 & -0.67 & -0.92 & -0.93 & -0.07 & 0.01 & -0.06 & - \\
\hline${ }^{2} J_{\mathrm{SnC} \equiv{ }^{13} \mathrm{C}}$ & -134.98 & -141.22 & -151.76 & -145.47 & -149.97 & -151.05 & -16.78 & 1.79 & -14.99 & -141.8 \\
\hline${ }^{3} J_{\mathrm{Sn}, 13} \mathrm{CH}_{3}$ & -13.77 & -11.33 & -16.46 & -11.60 & -16.18 & -16.24 & -2.69 & 0.28 & -2.41 & -12.8 \\
\hline${ }^{2} J_{\mathrm{PbC} \equiv 13 C}$ & 112.20 & 69.96 & 65.56 & 56.00 & 60.04 & 59.99 & -46.64 & -5.52 & -52.16 & 70.3 \\
\hline \multirow[t]{2}{*}{${ }^{3} J_{\mathrm{Pb},{ }^{13}} \mathrm{CH}_{3}$} & 11.48 & 7.27 & 11.46 & 6.34 & 10.62 & 10.62 & -0.02 & -0.84 & -0.86 & 9.2 \\
\hline & \multicolumn{10}{|c|}{$\mathrm{Me}_{3} \mathrm{XCCH}$} \\
\hline${ }^{2} J_{\mathrm{SiC} \equiv{ }^{13} \mathrm{C}}$ & -16.11 & -15.32 & -16.33 & -16.74 & -16.31 & -16.49 & -0.22 & 0.02 & -0.20 & -14.8 \\
\hline${ }^{2} J_{\mathrm{GeC} \equiv 13} \mathrm{C}$ & -5.26 & -5.00 & -5.27 & -5.04 & -5.23 & -5.26 & -0.01 & 0.04 & 0.03 & - \\
\hline${ }^{2} J_{\mathrm{SnC} \equiv{ }^{13} \mathrm{C}}$ & -89.66 & -83.36 & -87.10 & -79.94 & -85.40 & -85.98 & 2.56 & 1.70 & 4.26 & -85.6 \\
\hline${ }^{2} J_{\mathrm{PbC} \equiv 13 C}$ & 69.34 & -24.29 & -38.92 & -49.12 & -46.44 & -47.24 & -108.26 & -7.52 & -115.78 & - \\
\hline
\end{tabular}

${ }^{a}$ Average $J$ values are reported for atoms in similar chemical environments.

$b$ ZORA stands for the SO-ZORA results calculated using the ADF program package.

${ }^{c}$ SC stands for the scalar relativistic results calculated using the ReSpect program package by scaling the spin-orbit contribution to zero.

${ }^{d} \triangle \mathrm{SC}$ is scalar relativistic contribution obtained from the difference between SC/PBE0/dyall-cvtz and NR/PBE0/dyall-cvtz results.

$e \triangle \mathrm{SO}$ is the spin-orbit contribution obtained from the difference between the DKS/PBE0/dyall-cvtz and SC/PBE0/dyall-cvtz results.

${ }^{f} \Delta$ rel is the relativistic correction obtained from the difference between the DKS/PBE0/dyall-cvtz and NR/PBE0/dyall-cvtz results.

structures). The results for these two molecules are listed in Table VI. The comparison of the PBE and PBE0 functionals shows that PBE0 reproduces the experimental results. Further improvements were obtained by adding solvent effect corrections predicted using SO-ZORA/PBE0/acetonitrile calculations to the DKS/PBE0 calculated results. For instance, the ${ }^{1} J_{\mathrm{PtP}}$ result obtained from the DKS/PBE0 calculation is $2024.08 \mathrm{~Hz}$, whereas the solvent effect corrected result is $2038.51 \mathrm{~Hz}$, to be compared with the experimental value of $2215 \mathrm{~Hz}$. These results demonstrate that the fourcomponent relativistic method has reached a level of maturity that makes it a convenient and accurate tool for the calculation of indirect spin-spin coupling constants of 'large' molecules involving heavy atoms.

\section{CONCLUSIONS}

In the present work, the chemical shifts and indirect spin-spin coupling constants of 12 molecules have been studied using non-relativistic, two- and four-component relativistic DFT calculations. The calculated indirect spin-spin coupling constants are compared with available experimental values. The full four-component relativistic approach together with the hybrid PBE0 exchangecorrelation functional gave the best agreement between the calculated and the experimental indirect spin-spin coupling constants. The predicted NMR parameters, for which experimental data are missing, are therefore reliable. The analysis of the scalar and spin-orbit contributions of the NMR parameters show that the main relativistic effect is due to scalar relativistic contraction of the s-shells, not due to the spin-orbit coupling. However, inclusion of both contributions is important for the quality of the results. The relativistic correction to both the chemical shifts and indirect spin-spin coupling constants are considerable, indicating the importance of using four-component relativistic approaches for the calculation of related NMR parameters. For the coupling constants involving the heavy atoms, the relativistic corrections are of the same order of magnitude compared to the non-relativistically calculated values. For the NMR parameter calculations of similar molecular systems involving heavy atoms, spin-orbit coupling gives only part of the relativistic effect and therefore a computational method that includes scalar relativistic effects is crucial. New accurate and reliable results are reported for all the chemical shifts and indirect spin-spin coupling constants that are not known experimentally.

It is important to mention that post-Hartree-Fock methods can provide better accuracy but at much higher computational cost. Since post-Hartree-Fock methods are presently limited to smaller molecular systems, they 
TABLE VI. ${ }^{n} J_{\mathrm{PX}}\left(\mathrm{X}={ }^{1} \mathrm{H},{ }^{31} \mathrm{P},{ }^{105} \mathrm{Pd},{ }^{195} \mathrm{Pt} ; \mathrm{n}=1,2\right)$ indirect spin-spin coupling constants (in Hz) calculated using different Hamiltonians, functionals and basis sets together with available experimental values. ${ }^{a}$

\begin{tabular}{|c|c|c|c|c|c|c|c|}
\hline \multirow[b]{2}{*}{${ }^{n} J_{\mathrm{PX}}$} & \multicolumn{2}{|c|}{ SO-ZORA } & \multirow[b]{2}{*}{$\Delta$ solv $^{d}$} & \multicolumn{3}{|c|}{ DKS } & \multirow[b]{2}{*}{ Exp. ${ }^{55}$} \\
\hline & PBE0 (gas phase) & PBE0 (solvent) & & PBE & PBE0 & PBE0 (total) & \\
\hline \multicolumn{8}{|c|}{$\left[\mathrm{Pd}\left(\mathrm{PCy}_{2} \mathrm{H}\right)_{3} \mathrm{Cl}\right]^{+}$} \\
\hline${ }^{1} J_{\mathrm{PdP}}^{b}$ & -147.28 & -147.57 & -0.29 & -155.65 & -172.52 & -172.81 & - \\
\hline${ }^{1} J_{\mathrm{PdP}}^{c}$ & -207.32 & -216.49 & -9.17 & -229.76 & -243.63 & -252.80 & - \\
\hline${ }^{1} J_{\mathrm{PH}}^{b}$ & 268.25 & 284.93 & 16.68 & 251.20 & 280.83 & 297.51 & 355 \\
\hline${ }^{1} J_{\mathrm{PH}}^{c}$ & 277.17 & 292.67 & 15.50 & 263.97 & 292.18 & 307.68 & 365 \\
\hline${ }^{2} J_{\mathrm{PP}}^{b}$ & 304.48 & 302.15 & -2.33 & 314.18 & 371.15 & 368.82 & - \\
\hline${ }^{2} J_{\mathrm{PP}}^{c}$ & -16.30 & -15.16 & 1.14 & -13.26 & -24.83 & -23.69 & - \\
\hline \multicolumn{8}{|c|}{$\left[\mathrm{Pt}\left(\mathrm{PCy}_{2} \mathrm{H}\right)_{3} \mathrm{Cl}\right]^{+}$} \\
\hline${ }^{1} J_{\mathrm{PtP}}^{b}$ & 1649.31 & 1663.74 & 14.43 & 1665.56 & 2024.08 & 2038.51 & $\overline{2215}$ \\
\hline${ }^{1} J_{\mathrm{PtP}}^{c}$ & 2543.61 & 2643.28 & 99.67 & 2749.93 & 3088.32 & 3187.99 & 3162 \\
\hline${ }^{1} J_{\mathrm{PH}}^{b}$ & 285.34 & 301.32 & 15.98 & 269.34 & 298.55 & 314.53 & 357 \\
\hline${ }^{1} J_{\mathrm{PH}}^{c}$ & 294.19 & 309.28 & 15.09 & 282.38 & 309.61 & 324.70 & 391 \\
\hline${ }^{2} J_{\mathrm{PP}}^{b}$ & 266.48 & 264.37 & -2.11 & 282.89 & 319.43 & 317.32 & - \\
\hline${ }^{2} J_{\mathrm{PP}}^{c}$ & -11.41 & -11.50 & -0.09 & -7.44 & -17.73 & -17.82 & - \\
\hline
\end{tabular}

${ }^{b}$ Is coupling between the second nucleus and P trans P.

${ }^{c}$ Is coupling between the second nucleus and $\mathrm{P}$ trans $\mathrm{Cl}$. ${ }^{d} \Delta$ solv is the solvent effect correction.

TABLE VII. Comparison of the ${ }^{n} J_{\mathrm{PbC}}$ and ${ }^{n} J_{\mathrm{PbH}}(\mathrm{n}=1-4)$, as well as ${ }^{1} J_{\mathrm{PtP}},{ }^{1} J_{\mathrm{PH}}$ and ${ }^{2} J_{\mathrm{PP}}$ spin-spin coupling constants calculated using different Hamiltonians and basis sets (in $\mathrm{Hz}$ ).

\begin{tabular}{|c|c|c|c|c|c|}
\hline & \multicolumn{2}{|c|}{ SO-ZORA/PBE0 } & \multicolumn{2}{|c|}{ DKS/PBE0 } & \multirow[t]{2}{*}{ Exp. ${ }^{45,55}$} \\
\hline & TZ2P & JCPL & cvtz & cvqz & \\
\hline \multicolumn{6}{|c|}{$\mathrm{Pb}(\mathrm{CCMe})_{4}$} \\
\hline${ }^{1} J_{\mathrm{Pb} C} \equiv$ & 1505.25 & 1770.47 & 1764.67 & 1776.91 & 1624.5 \\
\hline${ }^{2} J_{\mathrm{PbC} \equiv{ }^{13} \mathrm{C}}$ & 380.35 & 453.41 & 425.36 & 429.67 & 347.4 \\
\hline${ }^{3} \mathrm{~J}_{\mathrm{Pb}, 13} \mathrm{CH}_{3}$ & 28.89 & 33.72 & 40.01 & 40.16 & 30.5 \\
\hline${ }^{4} \mathrm{~J}_{\mathrm{Pb}, \mathrm{CH}}$ & -32.79 & -38.60 & -34.14 & -43.72 & -28.0 \\
\hline \multicolumn{6}{|c|}{$\mathrm{Me}_{2} \mathrm{~Pb}(\mathrm{CCMe})_{2}$} \\
\hline${ }^{1} J_{\mathrm{PbCH}}$ & 373.73 & 386.49 & 491.32 & 498.24 & 574.3 \\
\hline${ }^{1} J_{\mathrm{Pb} C} \equiv$ & 55.89 & -3.20 & -3.40 & -5.67 & 208.0 \\
\hline${ }^{2} J_{\mathrm{PbC} \equiv 13 \mathrm{C}}$ & 69.96 & 74.30 & 60.04 & 59.99 & 70.30 \\
\hline${ }^{2} \mathrm{JPb}, \mathrm{CH}_{3}$ & -62.05 & -101.34 & -119.20 & -120.30 & -100.9 \\
\hline${ }^{3} \mathrm{~J}_{\mathrm{Pb}, 13 \mathrm{CH}_{3}}$ & 7.27 & 8.54 & 10.62 & 10.62 & 9.20 \\
\hline${ }^{4} \mathrm{JPb}, \mathrm{CH}_{3}$ & -12.67 & -15.16 & -15.01 & -15.14 & -13.5 \\
\hline \multicolumn{6}{|c|}{$\mathrm{Me}_{3} \mathrm{PbCCH}$} \\
\hline${ }^{1} \mathrm{~J} \mathrm{PbCH}_{3}$ & 199.93 & 185.29 & 264.83 & 266.79 & - \\
\hline${ }^{1} J_{\mathrm{Pb} C} \equiv$ & -321.52 & -456.17 & -440.91 & -445.76 & - \\
\hline${ }^{2} \mathrm{~J}_{\mathrm{Pb}, \mathrm{CH}}$ & -44.69 & -83.01 & -63.47 & -53.26 & - \\
\hline${ }^{2} J_{\mathrm{PbC} \equiv 13} \mathrm{C}$ & -24.29 & -41.11 & -46.44 & -47.24 & - \\
\hline${ }^{3} J_{\mathrm{Pb}, \mathrm{CH}}$ & 16.29 & 18.67 & 18.46 & 18.62 & - \\
\hline \multicolumn{6}{|c|}{$\left[\mathrm{Pt}\left(\mathrm{PCy}_{2} \mathrm{H}\right)_{3} \mathrm{Cl}\right]^{+a}$} \\
\hline${ }^{1} J_{\mathrm{PtP}}^{b}$ & 1649.31 & 2095.59 & 2024.08 & 2103.15 & 2215 \\
\hline${ }^{1} J_{\mathrm{PtP}}^{c}$ & 2543.61 & 3241.53 & 3088.32 & 3099.03 & 3162 \\
\hline${ }^{1} J_{\mathrm{PH}}^{b}$ & 285.34 & 297.35 & 298.55 & 312.29 & 357 \\
\hline${ }^{1} J_{\mathrm{PH}}^{c}$ & 294.19 & 308.64 & 309.61 & 325.61 & 391 \\
\hline${ }^{2} J_{\mathrm{PP}}^{b}$ & 266.48 & 306.83 & 319.43 & 338.04 & - \\
\hline${ }^{2} J_{\mathrm{PP}}^{c}$ & -11.41 & -15.97 & -17.73 & -19.58 & - \\
\hline
\end{tabular}

${ }^{a}$ Since the molecule is large, the Dyall-vdz and Dyall-vtz basis sets were used instead of the cvtz and cvqz basis sets, respectively, for the DKS calculations.

${ }^{b}$ Is coupling between the second nucleus and $\mathrm{P}$ trans $\mathrm{P}$.

${ }^{c}$ Is coupling between the second nucleus and $\mathrm{P}$ trans $\mathrm{Cl}$.

are not considered in this work. Moreover, the indirect spin-spin coupling constants calculated using the SO-
ZORA Hamiltonian together with the hybrid PBE0 functional and JCPL basis sets are in good agreement with the results obtained from the four-component relativistic DFT calculations. The present study also demonstrates that the four-component relativistic method has reached a level of maturity that makes it a convenient and accurate tool to calculate indirect spin-spin coupling constants of large molecules involving heavy atoms.

\section{SUPPLEMENTARY MATERIAL}

See supplementary material for additional results of both the chemical shifts and indirect spin-spin coupling constants as well as the optimized geometries of all molecules.

\section{ACKNOWLEDGMENTS}

This work has received support from the Research Council of Norway through Grant №. 179568/V30 and has benefited from computer time provided by the Norwegian supercomputing program NOTUR (Grant No. NN4654K). I am also grateful to the anonymous reviewers and Prof. Kenneth Ruud for their constructive comments.

${ }^{1}$ P. Pyykkö, 'Theory of NMR Parameters. From Ramsey to Relativity, 1953 to 1983 ' in Calculation of NMR and EPR Parameters, Edited by M. Kaupp, M. Buhl and V. G. Malkin (Wiley-VCH Verlag GmbH Co. KGaA, 2004) Chap. 2, pp 7-19.

${ }^{2}$ H. Gunther, NMR Spectroscopy: Basic Principles, Concepts and Applications in Chemistry, volume 3, 2013.

${ }^{3}$ J. Autschbach and S. Zheng, Annual Reports on NMR Spectroscopy 67, 1 (2009).

${ }^{4}$ M. Bühl and T. van Mourik, WIREs Comput. Mol. Sci. 1, 634 (2011).

${ }^{5}$ T. Helgaker, M. Jaszuński, and K. Ruud, Chem. Rev. 99, 293 (1999). 
${ }^{6}$ J. Autschbach and T. Ziegler, 'Relativistic Calculations of SpinSpin Coupling Constants of Heavy Nuclei' in Calculation of NMR and EPR Parameters, Edited by M. Kaupp, M. Buhl and V. G. Malkin (Wiley-VCH Verlag GmbH Co. KGaA, 2004) Chap. 15, pp 249-264.

${ }^{7}$ L. Visscher, T. Enevoldsen, T. Saue, H. J. A. Jensen, and J. Oddershede, J. Comput. Chem. 20, 1262 (1999).

${ }^{8}$ M. Repisky, S. Komorovsky, O. L. Malkina, and V. G. Malkin, Chem. Phys. 356, 236 (2009).

${ }^{9}$ T. B. Demissie, N. Kostenko, S. Komorovsky, M. Repisky, J. Isaksson, A. Bayer, K. Ruud, J. Phys. Org. Chem. 28, 723 (2015).

${ }^{10}$ K. Ø. Hanssen, B. Schuler, A. J. Williams, T. B. Demissie, E. Hansen, J. H. Andersen, J. Svenson, K. Blinov, M. Repisky, F. Mohn, G. Meyer, J. -S. Svendsen, K. Ruud, M. Elyashberg, L. Gross, M. Jaspars, J. Isaksson, Angew. Chem. Int. Ed. 51, 12238 (2012).

${ }^{11}$ T. B. Demissie, M. Jaszunski, S. Komorovsky, M. Repisky, and K. Ruud, J. Chem. Phys. 143, 164311 (2015).

${ }^{12}$ T. B. Demissie, M. Repisky, S. Komorovsky, J. Isaksson, J. Svendsen, H. Dodziuk, K. Ruud, J. Phys. Org. Chem. 26, 679 (2013).

${ }^{13}$ T. B. Demissie, M. Jaszuński, E. Malkin, S. Komorovsky, and K. Ruud, Mol. Phys. 113, 1576 (2015)

${ }^{14}$ E. van Lenthe, E. J. Baerends, and J. G. Snijders, J. Chem. Phys. 101, 9783 (1994).

${ }^{15}$ E. van Lenthe, A. Ehlers, and E. J. Baerends, J. Chem. Phys. 110, 8943 (1999).

${ }^{16}$ E. Malkin, S. Komorovsky, M. Repisky, T. B. Demissie, and K. Ruud, J. Phys. Chem. Lett. 4, 459 (2013).

${ }^{17}$ K. Ruud, T. B. Demissie, and M. Jaszuński, J. Chem. Phys. 140, 194308 (2014).

${ }^{18}$ ReSpect, version 4.0.0, 2016; Relativistic Spectroscopy DFT program of authors S. Komorovsky, M. Repisky, V. G. Malkin, O. L. Malkina, M. Kaupp, K. Ruud, with contributions from R. Bast, U. Ekstrom, M. Kadek, S. Knecht, L. Konecny, E. Malkin, I. Malkin-Ondik. (see www.respectprogram.org).

${ }^{19}$ S. Komorovsky, M. Repisky, O. L. Malkina, V. G. Malkin, I. Malkin Ondik, M. Kaupp, J. Chem. Phys. 128, 104101 (2008).

${ }^{20}$ S. Komorovsky, M. Repisky, O. L. Malkina, and V. G. Malkin, J. Chem. Phys. 132, 154101 (2010).

${ }^{21}$ A. Wodyński, M. Repisky, and M. Pecul, J. Chem. Phys. 137, 014311 (2012).

${ }^{22}$ P. Pyykkö, E. Pajanne, and M. Inokuti, Int. J. Quantum Chem. 7, 785 (1973).

${ }^{23}$ P. Pyykkö and J. Jokisaari, Chem. Phys. 10, 293 (1975).

${ }^{24}$ P. Pyykkö, Chem. Phys. 22, 289 (1977).

${ }^{25}$ T. Enevoldsen, L. Visscher, T. Saue, H. J. A. Jensen, and J. Oddershede, J. Chem. Phys. 112, 3493 (2000).

${ }^{26}$ S. Kirpekar, T. Enevoldsen, J. Oddershede, and W. T. Raynes, Mol. Phys. 91, 897 (1997).

${ }^{27}$ E. J. Baerends, J. Autschbach, A. Berces, F. M. Bickelhaupt, C. Bo, P. M. Boerrigter, L. Cavallo, D. P. Chong, L. Deng, R. M. Dickson, D. E. Ellis, M. van Faassen, L. Fischer, T. H. Fan, C. Fonseca Guerra, S. J. A. van Gisbergen, J. A. Groeneveld, O. V. Gritsenko, M. Gruning, F. E.Harris, P. van den Hoek, C. R. Jacob, H. Jacobsen, L. Jensen, G. van Kessel, F. Kootstra, E. van Lenthe, D. A. McCormack, A. Michalak, J. Neugebauer, V. P. Osinga, S. Patchkovskii, P. H. T. Philipsen, D. Post, C. C. Pye, W. Ravenek, P. Ros, P. R. T. Schipper, G. Schreckenbach, J. G. Snijders, M. Sola, M. Swart, D. Swerhone, G. teVelde, P. Vernooijs, L. Versluis, L. Visscher, O. Visser, F. Wang,
T. A. Wesolowski, E. van Wezenbeek, G. Wiesenekker, S. Wolff, T. Woo, A. Yakovlev, T. Ziegler, ADF2016.103, SCM, Theoretical Chemistry, Vrije Universiteit, Amsterdam, The Netherlands, http://www.scm.com, 2016.

${ }^{28}$ C. Adamo and V. Barone, J. Chem. Phys. 110, 6158 (1999).

${ }^{29}$ S. Grimme, J. Comput. Chem. 25, 1463 (2004).

${ }^{30}$ E. van Lenthe and E. J. Baerends, J. Comput. Chem. 24, 1142 (2003).

${ }^{31}$ J. P. Perdew, K. Burke, and M. Ernzerhof, Phys. Rev. Lett. 77, 3865 (1996).

${ }^{32}$ K. G. Dyall, Unpublished Basis Sets, personal communication, 2016, also available from the Dirac web site, http://dirac.chem.sdu.dk.

${ }^{33}$ P. Manninen, K. Ruud, P. Lantto, and J. Vaara, J. Chem. Phys. 122, 114107 (2005).

${ }^{34}$ J. I. Melo, M. C. R. de Azua, C. G. Giribet, G. A. Aucar, and R. H. Romero, J. Chem. Phys. 118, 471 (2003).

${ }^{35}$ R. M. Dickson and T. Ziegler, J. Phys. Chem. 100, 5286 (1996). ${ }^{36}$ J. Autschbach and T. Ziegler, J. Chem. Phys. 113, 936 (2000).

${ }^{37}$ J. Autschbach and T. Ziegler, J. Chem. Phys. 113, 9410 (2000).

${ }^{38} \mathrm{~S}$. Moncho and J. Autschbach, J. Chem. Theory Comput. 6, 223 (2010).

${ }^{39}$ F. London, J. Phys. Radium 8, 397 (1937).

${ }^{40}$ K. Wolinski, J. F. Hinton, and P. Pulay, J. Am. Chem. Soc. 112, 8251 (1990).

${ }^{41}$ A. Klamt and G. Schuurmann, J. Chem. Soc., Perkin Trans. 2, 799 (1993).

${ }^{42}$ E. R. Cohen, T. Cvitas, J. G. Frey, B. Holmstrom, K. Kuchitsu, R. Marquardt, I. Mills, F. Pavese, M. Quack, J. Stohner, H. L. Strauss, M. Takami, A. J. Thor, Quantities, Units and Symbols in Physical Chemistry, IUPAC Green Book, 3rd ed. (IUPAC and RSC Publishing, Cambridge, 2008), 2nd Printing.

${ }^{43}$ P. Pyykkö, A. Gorling, and N. Rosch, Mol. Phys. 61, 195 (1987).

${ }^{44}$ M. Kaupp, O. L. Malkina, V. G. Malkin, and P. Pyykkö, Chem. Eur. J. 4, 118 (1998).

${ }^{45}$ B. Wrackmeyer, K. H. von Locquenghien, E. Kupce, and A. Sebald, Mag. Reson. Chem. 31, 45 (1993).

${ }^{46}$ M. Kaupp, O. L. Malkina, V. G. Malkin, and P. Pyykkö, Chem. Eur. J. 4, 118 (1998).

${ }^{47}$ B. Martin and J. Autschbach, Phys. Chem. Chem. Phys. 18, 21051 (2016).

${ }^{48}$ A. Wodyński, A. Gryff-Keller, and M. Pecul, J. Chem.l Theory Comput. 9, 1909 (2013).

${ }^{49}$ A. Wodyński, O. L. Malkina, and M. Pecul, J. Phys. Chem. A 120, 5624 (2016).

${ }^{50}$ M. Pecul and K. Ruud, Magn. Reson. Chem. 42, S128 (2004).

${ }^{51}$ T. C. Ramalho, D. H. Pereira, and W. Thiel, J. Phys. Chem. A 115, 13504 (2011).

${ }^{52}$ M. Barfield and M. D. Johnston, Chem. Rev. 73, 53 (1973).

${ }^{53}$ K. Ruud, L. Frediani, R. Cammi, and B. Mennucci, Int. J. Mol. Sci. 4, 119 (2003).

${ }^{54}$ J. Autschbach and T. Ziegler, J. Am. Chem. Soc. 123, 3341 (2001).

${ }^{55}$ R. J. Forder, I. S. Mitchel, G. Reid, and R. H. Simpson, Polyhedron 13, 2129 (1994).

${ }^{56} \mathrm{~K}$. Jackowski and M. Jaszuński, editors, Gas-phase NMR, Royal Society of Chemistry, 2016.

${ }^{57}$ M. G. Nicol, C. A. Fleming, and R. L. Paul, The chemistry of the extraction of gold, in The Extractive Metallurgy of Gold in South Africa, edited by G. G. Stanley, volume M7 of The South African Institute of Mining and Metallurgy Monograph Series, The South African Institute of Mining and Metallurgy, 1987.

${ }^{58}$ P. Pyykkö and J. Jokisaari, Chem. Phys. 10, 293 (1975). 